\title{
Tooth loss and cancer risk: a dose-response meta analysis of prospective cohort studies
}

\author{
Jun Shi ${ }^{1}$, Weidong Leng ${ }^{1}$, Lunhua Zhao ${ }^{2}$, Cai Deng ${ }^{1}$, Chenli $\mathrm{Xu}^{2}$, Jue Wang ${ }^{2}$, Yu \\ Wang $^{3}$ and Xingchun Peng ${ }^{2,3,4}$ \\ ${ }^{1}$ Department of Stomatology, Taihe Hospital, Hubei University of Medicine, Shiyan, Hubei, 442000, China \\ ${ }^{2}$ School of Basic Medical Sciences, Hubei University of Medicine, Shiyan, Hubei, 442000, China \\ ${ }^{3}$ Department of Ultrasonography, Xiangyang No.1 People's Hospital, Hubei University of Medicine, Xiangyang, Hubei, 441000 , \\ China \\ ${ }^{4}$ Department of Oncology, Suizhou Hospital, Hubei University of Medicine, Suizhou, Hubei, 441300, China \\ Correspondence to: Xingchun Peng, email: 3537348127@qq.com \\ Yu Wang, email: wangyu595@sina.com \\ Keywords: cancer; tooth loss; dose-response relationship; meta analysis \\ Received: April 27, 2017 Accepted: October 25, 2017 Epub: December 16, 2017 Published: March 13, 2018
}

Copyright: Shi et al. This is an open-access article distributed under the terms of the Creative Commons Attribution License 3.0 (CC BY 3.0), which permits unrestricted use, distribution, and reproduction in any medium, provided the original author and source are credited.

\section{ABSTRACT}

Conflicting results to identify the relationship between tooth loss and cancer risk. Therefore, a dose-response meta-analysis was performed to clarify and quantitative assessed the correlation between tooth loss and cancer risk. Up to March 2017, 25 observational epidemiological studies were included in current meta-analysis. Tooth loss was significantly associated with a higher risk of cancer. Additionally, tooth loss was associated with significantly a higher risk of esophageal cancer, gastric cancer, head and neck cancer, colorectal cancer, pancreas cancer, lung cancer, prostate cancer, bladder cancer and hematopoietic cancer. Subgroup analysis showed consistent findings. Furthermore, a significant dose-response relationship was observed between tooth loss and cancer risk. Increasing per 10 of tooth loss was associated with a $9 \%$ increment of cancer risk, $14 \%$ increment of esophageal cancer risk, $9 \%$ increment of gastric cancer risk, $31 \%$ increment of head and neck cancer risk, $4 \%$ increment of colorectal cancer risk, $7 \%$ increment of pancreas cancer risk, $19 \%$ increment of lung cancer risk, $2 \%$ increment of bladder cancer risk and $3 \%$ increment of hematopoietic cancer risk. Considering these promising results, tooth loss might be harmful for health. Large sample size, different ethnic population and different cancer type are warranted to validate this association.

\section{INTRODUCTION}

Cancer has to be the second-leading cause in 2015 that caused over 8.8 million deaths worldwide in 2015 [1]. Due to countries geographical environment, living habits, cancer incidence is very different. The incidence of cancer in developing countries such as Africa, Asia and South America is the most severe. A total of 14 million cancer cases were added worldwide and 8.2 million people died in 2012. Among them, China added 3.07 million cancer patients and caused about 2.2 million deaths, accounting for $21.9 \%$ of the total global deaths. The incidence of cancer in developed countries is still higher than in developing countries. Residents of North
America and Europe are the most vulnerable to cancer, but China has a large population base, making it the country with the highest number of cancer deaths throughout the world. As more and more people in developing countries improve their living standards and dietary patterns change, the chances of cancer have increased significantly in developing countries [2]. The etiology of cancer involves both genetic and environmental factors. Therefore, understanding the impact of environmental factors on cancer will help to prevent cancer.

Oral cavity is an important part of the body, and is starts in the digestive system, mainly by the lip and cheek, tongue and palate, salivary glands, teeth and jaw, with mastication, swallowing, speech and feeling, and 
other functions, which maintain the normal shape of maxillofacial. Oral health is an important part of human health. The World Health Organization (WHO) identifies dental health as one of the top ten criteria for human health. Poor oral health may increase systemic inflammation, resulting in a local overly aggressive immune response, and thus could have important implications for cancer development. Periodontal disease and tooth loss are two common oral health measures [3]. Tooth loss has been considered to impact quality of life [4], and been known to considerably influence food choice, diet, nutrition intake, and esthetics [5].

Previous studies have examined the correlation between tooth loss and cancer risk [6-30]. However, the result remains controversial. Additionally, no study to quantitative assessed tooth loss in relation to cancer risk. Thus, we performed this dose-response meta-analysis to clarify and quantitative assessed the correlation between tooth loss and cancer risk.

\section{MATERIALS AND METHODS}

This meta-analysis was conducted according to the Meta-analysis Of Observational Studies in Epidemiology (MOOSE) checklist [31].

\section{Search strategy}

We included eligible studies to investigate the relationship between tooth loss and cancer risk in general adult populations. To develop a flexible, non-linear, $r$ meta-regression model, we required that an eligible study should have categorized into 3 or more levels.

PubMed and EMBASE were searched for studies that contained risk estimates for the outcomes of cancer and were published update to March 2017, with keywords including "dentition" [MeSH] OR "tooth loss" [MeSH] OR "edentulous" [MeSH] OR "lost of tooth" [MeSH] AND “cancer" $[\mathrm{MeSH}]$ OR "tumor" [MeSH] OR "neoplasms" [MeSH]. We refer to the relevant original essays and commentary articles to determine further relevant research.

\section{Study selection}

Two independent researchers investigate information the correlation between tooth loss and cancer risk: outcome was cancer. Moreover, we precluded nonhuman studies, reviews, meta-analyses, editorials and published letters.

\section{Data extraction}

Use standardized data collection tables to extract data. Each eligible article information was extracted by two independent researchers. We extracted the following information: first author; publication year; age; country; sex; cases and participants; the categories of tooth loss; relative risk or odds ratio (OR). We collect the risk estimates with multivariable-adjusted [32]. According to the Newcastle-Ottawa scale, quality assessment was performed for non-randomized studies [33]. The disagreements were resolved through consensus by all the authors.

\section{Statistical analysis}

We pooled relative risk estimates to measure the association between tooth loss and cancer; the hazard ratio were considered equivalent to the relative risk [34]. Results in different subgroups of tooth loss and cancer risk were treated as two separate reports.

Due to different definitions cut-off points in the included studies for categories, we performed a relative risk estimates by the method recommended by Greenland, Longnecker and Orsini and colleagues [35]. Dose of tooth loss used the median tooth loss. If the median tooth loss category was not available, the midpoint of the upper and lower boundaries was considered the dose of each category. In addition, using restricted cubic splines to evaluate the non-linear association between tooth loss and cancer risk, with three knots at the 10th, 50th, and 90th percentiles of the distribution. A flexible meta-regression based on restricted cubic spline (RCS) function was used to fit the potential non-linear trend, and generalized least-square method was used to estimate the parameters. This procedure treats tooth loss (continuous data) as an independent variable and $\log R \mathrm{R}$ of diseases as a dependent variable, with both tails of the curve restricted to linear. A $P$ value is calculated for linear or non-linear by testing the null hypothesis that the coefficient of the second spline is equal to zero [32].

The between-study heterogeneity was assessed by $Q$-statistic (signifcance level at $P \leq 0.10$ ) and the $\mathrm{I}^{2}$ statistic. STATA software 14.0 (STATA Corp, College Station, TX, USA) was using in all analyses. $P<0.05$ was considered signifcant for all tests.

\section{RESULTS}

\section{Literature search results}

We identifed 3088 relevant citations after removing duplicates. Reviewing their titles and abstracts, 3021 citations were excluded. The remaining 67 citations were assessed in more detail for eligibility by reading the full text. Among them, 43 were excluded, after review reference, one articles was included. Finally, 25 studies were used for the final data synthesis [6-30]. The flow chart of literature searching was presented in Figure 1, and the data were extracted. These studies were published update to March 2017. 


\section{Study characteristics}

The characteristics of the included studies of tooth loss and cancer risk are shown in the Table 1 and Supplementary Table 1. Among the selected studies, nine focused on esophageal cancer [6-13, 24], five focused on gastric cancer $[6,7,12,13,15]$, eleven focused on head and neck cancer [11-13, 16-20, 23, 25, 26], four focused on colorectal cancer [12, 13, 28, 29], five focused on pancreas cancer [12-14, 21, 30], two focused on lung cancer [12, 13], two focused on prostate cancer $[12,13]$ and two focused on bladder cancer $[12,13]$. Results in different subgroups were treated as two separate reports. Finally, Eighty-one independent reports from twenty five studies investigated the association between tooth loss and cancer.

\section{Tooth loss and overall cancer risk}

Eighty-one independent reports from twenty five studies investigated the association between tooth loss and cancer [6-30]. Compared with the lowest tooth loss, tooth loss is significantly associated with a higher risk of cancer risk (RR:1.06; 95\% CI, 1.02-1.09; $P<0.001$ ) (Table 2). Additionally, a dose-response analysis revealed that each 10 tooth loss was associated with a $9 \%$ incremental in cancer risk (RR: 1.09; 95\% CI, 1.05-1.13) (Figure 2).
A cubic spline model revealed an positive non-linear correlation between tooth loss and cancer $(P<0.001$ for non-linearity; Figure 2).

\section{Tooth loss and esophageal cancer}

Ten independent reports from nine studies investigated the association between tooth loss and esophageal cancer [6-13, 24]. Compared with the lowest tooth loss, tooth loss is significantly associated with a higher risk of esophageal cancer (RR:1.18; 95\% CI, $1.04-1.31 ; P<0.001$ ) (Table 2). Furthermore, tooth loss is significantly associated with esophageal cancer risk in Caucasia (RR:1.12; 95\% CI, 1.02-1.21; $P<.001$ ) (Table 2) and Asia (RR:1.26; 95\% CI, 1.08-1.44; $P<.001$ ) (Table 2). Additionally, a dose-response analysis revealed that each 10 tooth loss was associated with a $14 \%$ incremental in esophageal cancer risk (RR: 1.14; 95\% CI, 1.05-1.25) (Figure 3). A cubic spline model revealed an positive non-linear correlation between tooth loss and esophageal cancer $(P<0.001$ for non-linearity; Figure 3$)$.

\section{Tooth loss and gastric cancer}

Nine independent reports from five studies investigated the association between tooth loss and gastric

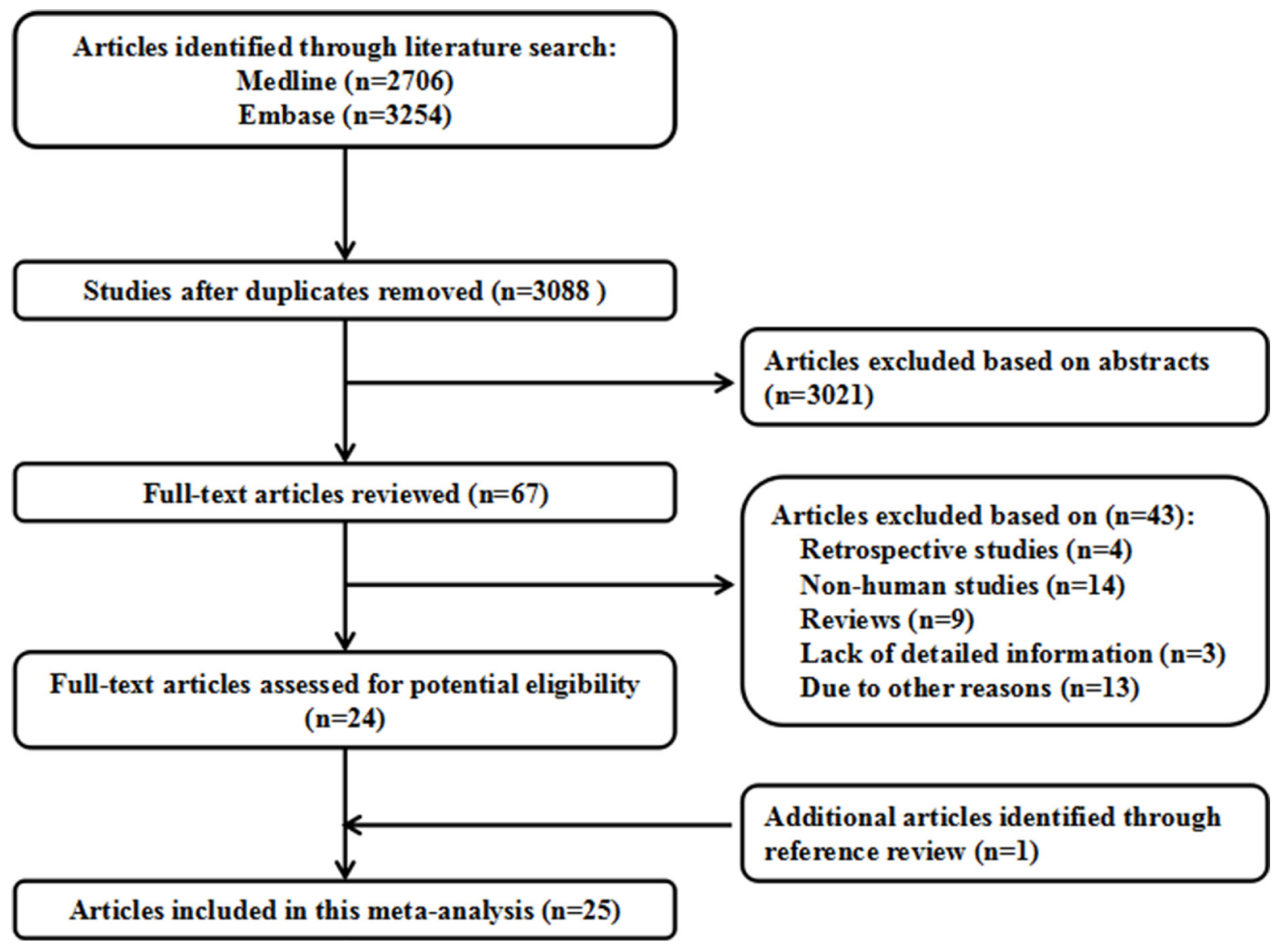

Figure 1: Flow diagram of the study selection process. 
Table 1: Characteristics of participants in included studies of tooth loss in relation to risk of cancer

\begin{tabular}{|c|c|c|c|c|c|c|c|}
\hline Author (year) & Study design & Country & $\begin{array}{c}\text { Sex of } \\
\text { population }\end{array}$ & $\begin{array}{c}\text { Age at } \\
\text { baseline } \\
\text { (years) }\end{array}$ & $\begin{array}{c}\text { No of } \\
\text { participants }\end{array}$ & Endpoints (cases) & $\begin{array}{l}\text { Quality } \\
\text { score }\end{array}$ \\
\hline Abnet et al. (2001) & cohort & China & Mix & $40-69$ & 29548 & $\begin{array}{l}\text { Esophageal cancer (620) } \\
\text { Gastric cancer (533) }\end{array}$ & 8 \\
\hline Abnet et al. (2005) & cohort & Finnish & Mix & $50-69$ & 29124 & $\begin{array}{l}\text { Esophageal cancer (49) } \\
\text { Gastric cancer (245) }\end{array}$ & 8 \\
\hline Abnet et al. (2008) & case-control & Iran & Mix & $>18$ & 843 & Esophageal cancer (283) & 6 \\
\hline Dar et al. (2013) & case-control & Kashmir & Mix & 61.6 & 2367 & Esophageal cancer (703) & 6 \\
\hline Dye et al. (2007) & case-control & China & Mix & $40-67$ & 977500 & Esophageal cancer (579) & 6 \\
\hline Guha et al. (2007) & case-control & $\begin{array}{l}\text { USA and } \\
\text { Europe }\end{array}$ & Mix & any age & $\begin{array}{l}\text { Europe (4110) } \\
\text { USA (1852) }\end{array}$ & $\begin{array}{c}\text { Europe: } \\
\text { Esophageal cancer (91) } \\
\text { Head and neck cancer (507) } \\
\text { USA } \\
\text { Esophageal cancer (95) } \\
\text { Head and neck cancer (1457) }\end{array}$ & 7 \\
\hline Hiraki et al. (2008) & case-control & Japan & Mix & 58.0 & 15720 & $\begin{array}{c}\text { Head and neck (429) } \\
\text { Esophagus (354) } \\
\text { Stomach (702) } \\
\text { Colon (662) } \\
\text { Liver (167) } \\
\text { Pancreas (178) } \\
\text { Lung (909) } \\
\text { Breast (756) } \\
\text { Uterus (429) } \\
\text { Ovary (103) } \\
\text { Prostate (136) } \\
\text { Bladder (62) } \\
\text { Thyroid (121) } \\
\text { Lymphoma (232) }\end{array}$ & 7 \\
\hline Michaud et al. (2008) & cohort & USA & Male & $40-75$ & 48375 & $\begin{array}{c}\text { Total (5720) } \\
\text { Lung (678) } \\
\text { Oropharyngeal (118) } \\
\text { Esophageal (131) } \\
\text { Stomach (106) } \\
\text { Pancreatic (253) } \\
\text { Colorectal (1043) } \\
\text { Kidney (271) } \\
\text { Lung (678) } \\
\text { Bladder (543) } \\
\text { Prostate (541) } \\
\text { Hematopoietic (934) } \\
\text { Brain (132) } \\
\text { Skin Melanoma (698) } \\
\text { Non-Hodgkin lymphoma (524) } \\
\text { Leukemia (250) } \\
\text { Multiple myeloma (141) }\end{array}$ & 8 \\
\hline Michaud et al. (2007) & cohort & USA & Male & $40-75$ & 51529 & Pancreatic (216) & 8 \\
\hline Shakeri et al. (2013) & case-control & Iran & Mix & $40-75$ & 922 & Gastric (588) & 6 \\
\hline Balaram et al. (2002) & case-control & India & Mix & $22-58$ & 1164 & oral cavity (584) & 5 \\
\hline $\begin{array}{l}\text { Bundgaard et al. } \\
\text { (1995) }\end{array}$ & case-control & Denmark & Mix & $<75$ & 559 & oral cavity (161) & 6 \\
\hline Garrote et al. (2001) & case-control & Cuba & Mix & 60 & 400 & oral cavity (200) & 5 \\
\hline $\begin{array}{l}\text { Lissowska et al. } \\
\text { (2003) }\end{array}$ & case-control & Poland & Mix & $23-80$ & 244 & oral cancer (122) & 6 \\
\hline Talamini et al. (2000) & case-control & Italian & Mix & $27-86$ & 274 & oral cancer (131) & 6 \\
\hline $\begin{array}{l}\text { Stolzenberg-Solomon } \\
\text { et al. (2003) }\end{array}$ & cohort & Finland & Male & $50-69$ & 29104 & pancreatic cancer (174) & 8 \\
\hline
\end{tabular}


cohort

USA

Bertrand et al. (2017)

Chen et al. (2016)

Chen et al. (2016)

Zuo et al. (2014)

Divaris et al. (2010)

Liu et al. (2016)

Momen-Heravi et al. (2017)

Ren et al. (2016)

Huang et al. (2016)

$\begin{array}{ccccc}\text { case-control } & \text { China } & \text { Female } & 20-80 & 1246 \\ \text { case-control } & \text { China } & \text { Mix } & 40-85 & 1386 \\ \text { case-control } & \text { China } & \text { Mix } & >18 & 317 \\ \text { case-control } & \text { USA } & \text { Mix } & 26-80 & 2650 \\ \text { case-control } & \text { China } & \text { Mix } & 20-74 & 5124 \\ & & & & \\ \text { cohort } & \text { USA } & \text { Female } & 39-55 & 77443 \\ & & & & \\ \text { case-control } & \text { China } & \text { Mix } & 40-79 & 6619 \\ \text { cohort } & \text { Sweden } & \text { Mix } & 20-70 & 19924\end{array}$

in gastric cancer risk (RR: $1.09 ; 95 \% \mathrm{CI}, 1.01-1.18 ; P$ $<0.001$ ) (Figure 3). A cubic spline model revealed an positive non-linear correlation between tooth loss and gastric cancer $(P<0.001$ for non-linearity; Figure 3$)$.

\section{Tooth loss and head and neck cancer}

Nineteen independent reports from eleven studies investigated the association between tooth loss and head and neck cancer $[11-13,16-20,23,25,26]$. Compared

Head and Neck Cancer (1361) 6
NonHodgkin lymphoma (875)

lymphocytic leukemia/ (290)

diffuse large B-cell lymphomas

Follicular lymphomas (91)

$\begin{array}{ll}\text { Oral cancer (250) } & 6 \\ \text { Esophagus (616) } & 6 \\ \text { Oral cancer (150) } & 7\end{array}$

nasopharyngeal carcinoma

colorectal cancer (1165)

6
$2)$. Additionally, a dose-response analysis revealed that each 10 tooth loss was associated with a $9 \%$ incremental

cancer $[6,7,12,13,15]$. The results of tooth loss and with a higher risk of gastric cancer (RR: 1.09; 95\% CI, $1.03-1.16 ; P<0.001$ ) (Table 2). Furthermore, tooth loss is significantly associated with gastric cancer risk in Caucasia (RR:1.25; 95\% CI, 1.11-1.36; $P<0.001$ ) (Table 2) and Asia (RR:1.04; 95\% CI, 1.01-1.09; $P<0.001$ ) (Table

8

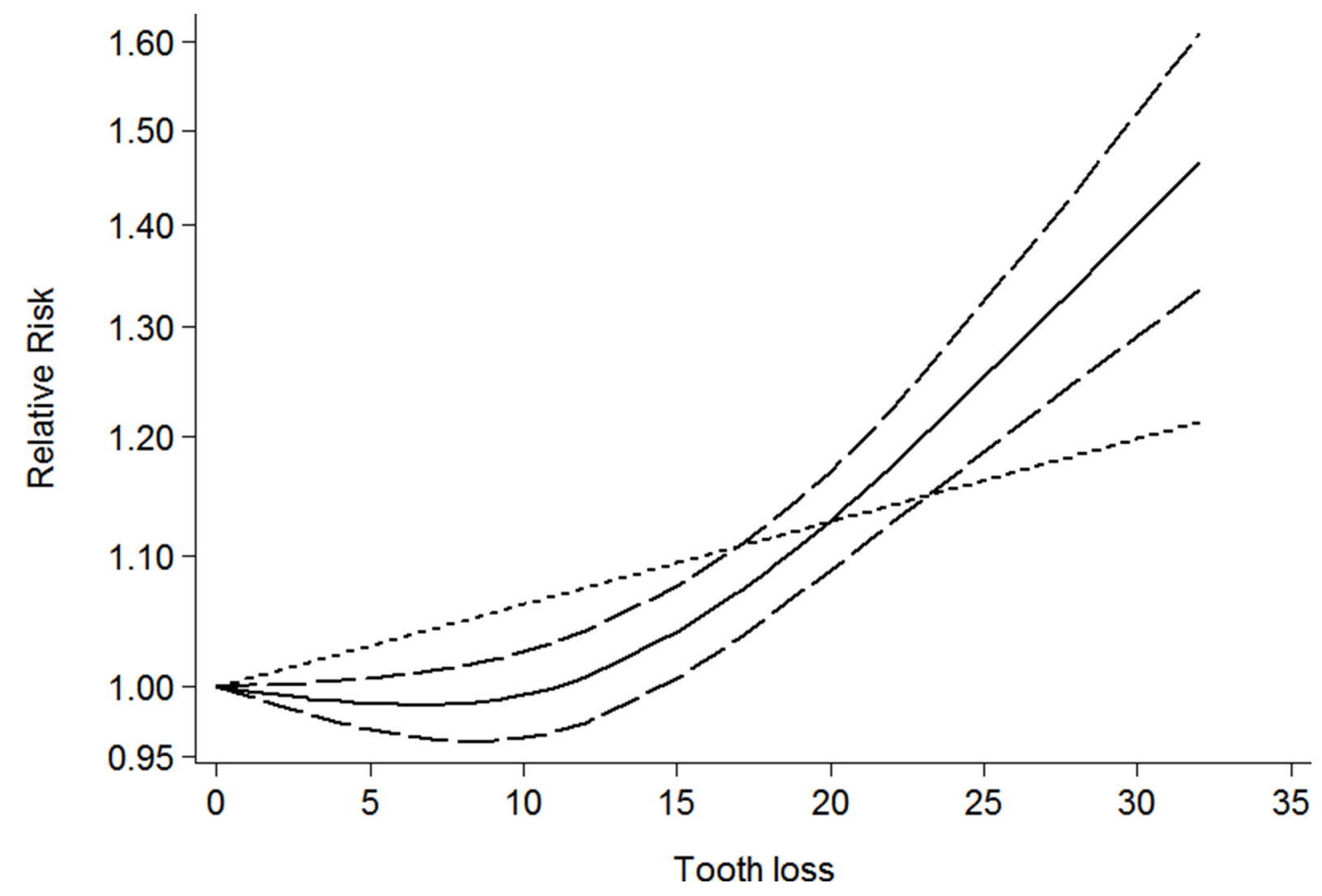

Figure 2: Dose-response relationship between tooth loss in relation to risk of overall cancer. 


\begin{tabular}{|c|c|c|c|c|c|}
\hline & No of reports & $\begin{array}{c}\text { Relative risk (95\% } \\
\text { CI) }\end{array}$ & P for heterogeneity & $\mathbf{I}^{2}$ & P for test \\
\hline Total & 81 & $1.06(1.02-1.09)$ & 0.000 & $51.2 \%$ & $<0.001$ \\
\hline \multicolumn{6}{|c|}{ Subgroup analyses for cancer } \\
\hline Esophageal cancer & 10 & $1.18(1.04-1.31)$ & 0.558 & $0.0 \%$ & $<0.001$ \\
\hline \multicolumn{6}{|c|}{ Subgroup analyses for Esophageal cancer } \\
\hline \multicolumn{6}{|l|}{ Study location } \\
\hline Caucasia & 6 & $1.12(1.02-1.21)$ & 0.520 & $0.0 \%$ & $<0.001$ \\
\hline Asia & 4 & $1.26(1.08-1.44)$ & 0.363 & $5.9 \%$ & $<0.001$ \\
\hline \multicolumn{6}{|l|}{ Study design } \\
\hline Case-control & 7 & $1.34(1.04-1.64)$ & 0.736 & $0.0 \%$ & $<0.001$ \\
\hline Cohort & 3 & $1.11(1.04-1.18)$ & 0.460 & $0.0 \%$ & $<0.001$ \\
\hline \multicolumn{6}{|l|}{ Study quality } \\
\hline Score $\geq 7$ & 3 & $1.11(1.04-1.18)$ & 0.460 & $0.0 \%$ & $<0.001$ \\
\hline Score $<7$ & 7 & $1.34(1.04-1.64)$ & 0.736 & $0.0 \%$ & $<0.001$ \\
\hline Gastric cancer & 9 & $1.09(1.03-1.16)$ & 0.763 & $0.0 \%$ & $<0.001$ \\
\hline \multicolumn{6}{|c|}{ Subgroup analyses for Gastric cancer } \\
\hline \multicolumn{6}{|l|}{ Study location } \\
\hline Caucasia & 6 & $1.25(1.11-1.36)$ & 0.737 & $0.0 \%$ & $<0.001$ \\
\hline Asia & 3 & $1.04(1.01-1.09)$ & 0.863 & $0.0 \%$ & $<0.001$ \\
\hline \multicolumn{6}{|l|}{ Study design } \\
\hline Case-control & 4 & $1.10(1.02-1.19)$ & 0.739 & $0.0 \%$ & $<0.001$ \\
\hline Cohort & 5 & $1.13(1.04-1.23)$ & 0.474 & $0.0 \%$ & $<0.001$ \\
\hline \multicolumn{6}{|l|}{ Study quality } \\
\hline Score $\geq 7$ & 5 & $1.13(1.04-1.23)$ & 0.474 & $0.0 \%$ & $<0.001$ \\
\hline Score $<7$ & 4 & $1.10(1.02-1.19)$ & 0.739 & $0.0 \%$ & $<0.001$ \\
\hline Head and neck cancer & 19 & $1.52(1.14-1.90)$ & 0.000 & $71.3 \%$ & $<0.001$ \\
\hline \multicolumn{6}{|c|}{ Subgroup analyses for Head and neck cancer } \\
\hline Oral cancer & 15 & $1.80(1.30-2.30)$ & 0.000 & $67.7 \%$ & $<0.001$ \\
\hline Pharynx & 2 & $1.14(1.05-1.23)$ & 0.295 & $5.7 \%$ & $<0.001$ \\
\hline Larynx cancer & 2 & $1.08(1.02-1.15)$ & 0.004 & $87.5 \%$ & $<0.001$ \\
\hline \multicolumn{6}{|l|}{ Study location } \\
\hline Caucasia & 11 & $1.15(1.04-1.26)$ & 0.004 & $61.2 \%$ & $<0.001$ \\
\hline Asia & 8 & $1.82(1.52-2.12)$ & 0.288 & $18.6 \%$ & $<0.001$ \\
\hline \multicolumn{6}{|l|}{ Study design } \\
\hline Case-control & 18 & $1.52(1.13-1.92)$ & 0.000 & $72.7 \%$ & $<0.001$ \\
\hline Cohort & 1 & $1.60(0.84-3.04)$ & 0.288 & $18.6 \%$ & 0.121 \\
\hline \multicolumn{6}{|l|}{ Study quality } \\
\hline Score $\geq 7$ & 9 & $1.13(1.04-1.23)$ & 0.001 & $70.1 \%$ & $<0.001$ \\
\hline Score $<7$ & 10 & $1.91(1.58-2.24)$ & 0.171 & $29.8 \%$ & $<0.001$ \\
\hline Colorectal cancer & 13 & $1.07(1.02-1.14)$ & 0.114 & $33.5 \%$ & $<0.001$ \\
\hline \multicolumn{6}{|c|}{ Subgroup analyses for Colorectal cancer } \\
\hline Colon & 5 & $1.09(1.02-1.17)$ & 0.330 & $13.2 \%$ & $<0.001$ \\
\hline Rectal & 3 & $1.08(1.01-1.17)$ & 0.082 & $60.0 \%$ & $<0.001$ \\
\hline
\end{tabular}


Study location

Caucasia

Asia

Study design

Case-control

Cohort

Study quality

Score $\geq 7$

Score $<7$

Pancreas cancer

Lung cancer

Prostate cancer

Bladder cancer

Hematopoietic cancer
6

7

$1.17(1.07-1.27)$

1.05 (1.01-1.09)

1.05 (1.01-1.09)

1.17 (1.07-1.27)

$1.16(1.06-1.25)$

$0.84(0.65-1.03)$

1.15 (1.05-1.19)

1.66 (1.34-1.97)

1.14 (1.03-1.25)

$1.23(1.12-1.35)$

1.07 (1.02-1.13)
0.692

0.986

$0.0 \%$

$0.0 \%$

$<0.001$

$<0.001$

0.986

0.692

$0.0 \%<0.001$

$0.0 \%<0.001$

0.669

0.970

$0.0 \%<0.001$

0.498

0.660

0.481

0.596

0.443
$0.0 \%$

0.316

$0.0 \%<0.001$

$0.0 \%<0.001$

$0.0 \%<0.001$

$0.0 \%<0.001$

$0.0 \%<0.001$ with the lowest tooth loss, tooth loss is significantly associated with head and neck cancer risk (RR:1.52; 95\% CI, 1.14-1.90; $P<0.001$ ) (Table 2). Furthermore, tooth loss is significantly associated with a higher risk of head and neck cancer in Caucasia (RR:1.15; 95\% CI, 1.04-1.26; $P<0.001$ ) (Table 2) and Asia (RR:1.82; 95\% CI, $1.52-$ $2.12 ; P<0.001$ ) (Table 2 ). Also, tooth loss is significantly associated with oral cancer (RR:1.80; 95\% CI, 1.30-2.30;

A

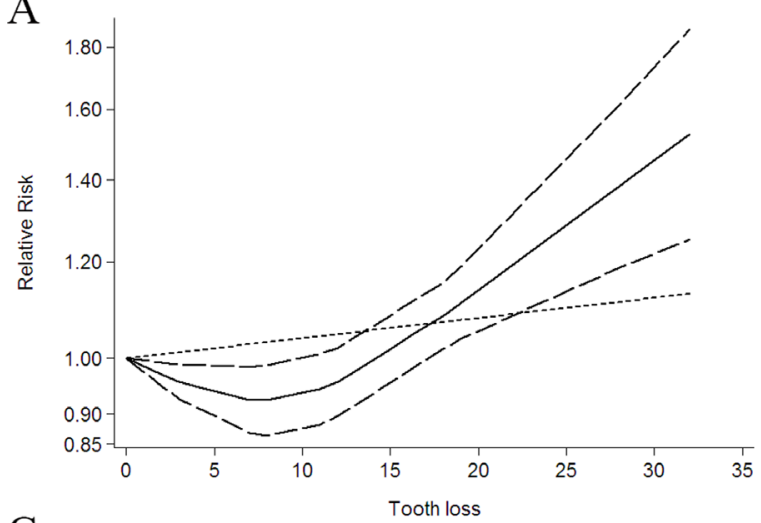

$\mathrm{C}$

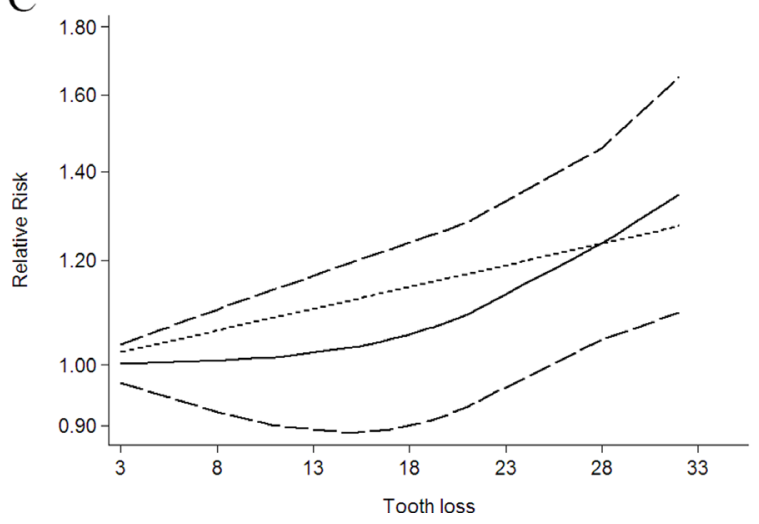

$P<0.001$ ) (Table 2), Pharynx cancer (RR:1.14; 95\% CI, 1.05-1.23; $P<0.001$ ) (Table 2) and Larynx cancer (RR:1.08; 95\% CI, 1.02-1.15; $P<0.001$ ) (Table 2). Additionally, a dose-response analysis revealed that each 10 tooth loss was associated with a $31 \%$ incremental in head and neck cancer risk (RR: 1.31 ; 95\% CI, 1.15-1.50; $P<0.001$ ) (Figure 3). A cubic spline model revealed an positive non-linear correlation between tooth loss and

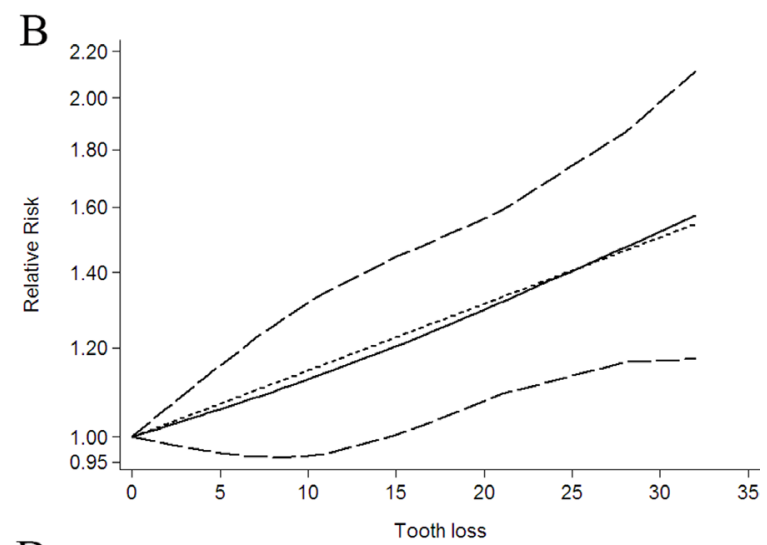

D

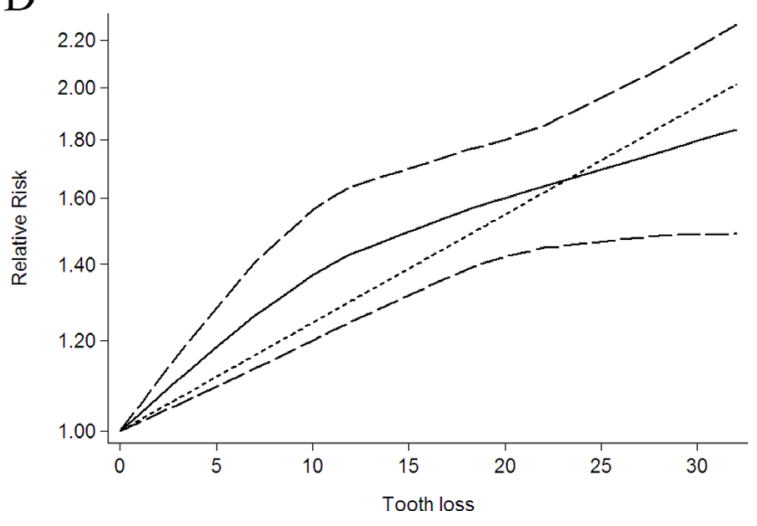

Figure 3: Dose-response relationship between tooth loss in relation to risk of cancer. (A) Colorectal cancer. (B) Esophageal cancer. (C) Gastric cancer. (D) Head and neck cancer. 
head and neck cancer cancer $(P<0.001$ for non-linearity; Figure 3).

\section{Tooth loss and colorectal cancer}

Thirteen independent reports from four studies investigated the association between tooth loss and colorectal cancer $[12,13,28,29]$. Compared with the lowest tooth loss, tooth loss is significantly associated with a higher risk of colorectal cancer (RR:1.07; 95\% CI, $1.02-1.14 ; P<0.001$ ) (Table 2). Furthermore, tooth loss is significantly associated with colorectal cancer risk in Caucasia (RR:1.17; 95\% CI, 1.07-1.27; $P<0.001$ ) (Table 2) and Asia (RR:1.05; 95\% CI, 1.01-1.09; $P<0.001$ ) (Table 2). Also, tooth loss is significantly associated with a higher risk of colon cancer (RR: 1.09 ; 95\% CI, $1.02-$ 1.17; $P<0.001$ ) (Table 2) and rectal cancer (RR:1.08; 95\% CI, 1.01-1.17; $P<0.001$ ) (Table 2). Additionally, a dose-response analysis revealed that each 10 tooth loss was associated with a 4\% incremental in colorectal cancer risk (RR:1.04; 95\% CI, 1.01-1.08; $P<0.001$ ) (Figure $3)$. A cubic spline model revealed an positive non-linear correlation between tooth loss and colorectal cancer $(P<$ 0.001 for non-linearity; Figure 3).
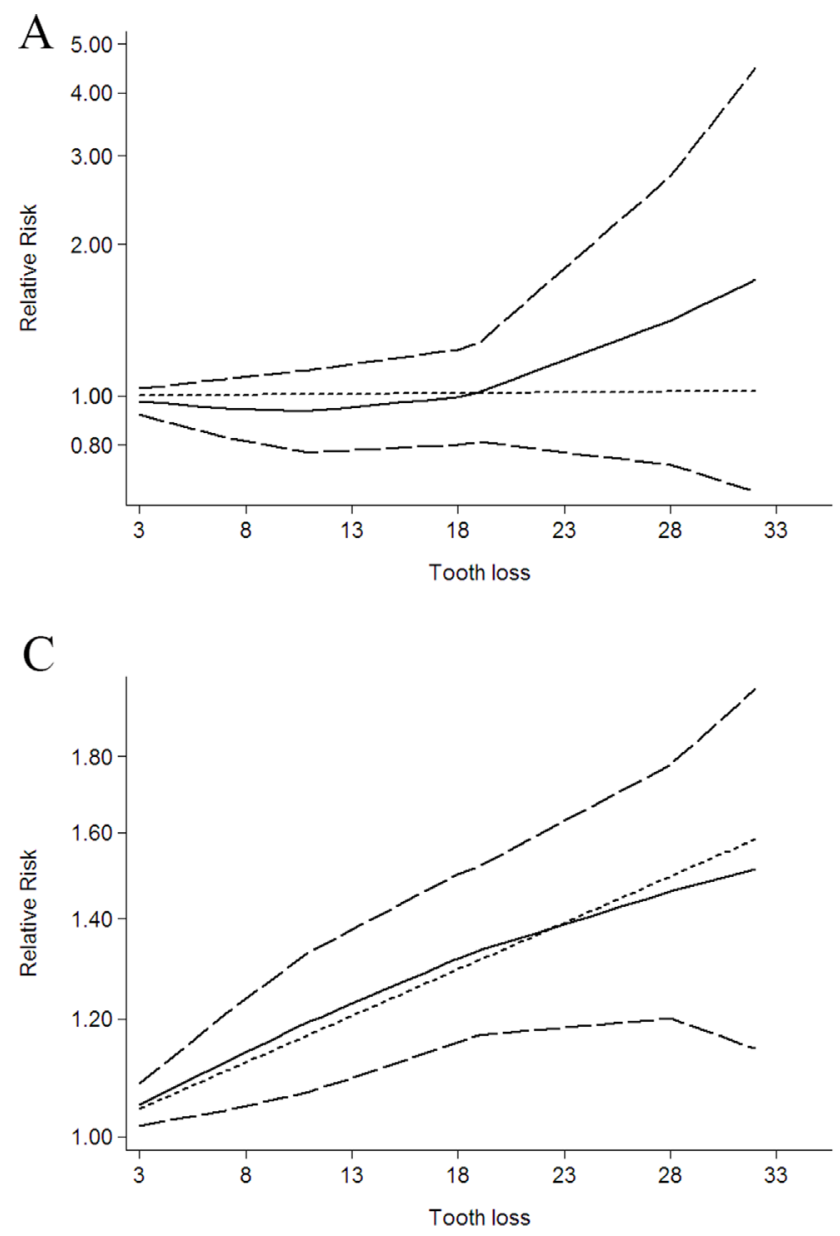

\section{Tooth loss and pancreas cancer}

Five independent reports from five studies investigated the association between tooth loss and pancreas cancer $[12-14,21,30]$. Compared with the lowest tooth loss, tooth loss is significantly associated with a higher risk of pancreas cancer (RR:1.15; 95\% CI, 1.05-1.19; $P<0.001$ ) (Table 2). Additionally, a doseresponse analysis revealed that each 10 tooth loss was associated with a 7\% incremental in pancreas cancer risk (RR:1.07; 95\% CI, 1.01-1.15; $P<0.001$ ) (Figure 4). A cubic spline model revealed an positive non-linear correlation between tooth loss and pancreas cancer $(P<$ 0.001 for non-linearity; Figure 4).

\section{Tooth loss and lung cancer}

Five independent reports from two studies investigated the association between tooth loss and lung cancer $[12,13]$. Compared with lowest tooth loss, tooth loss is significantly associated with a higher risk of lung cancer (RR: 1.66; 95\% CI, 1.34-1.97; $P<0.001$ ) (Table 2). Additionally, a dose-response analysis revealed that each 10 tooth loss was associated with a $19 \%$ incremental in
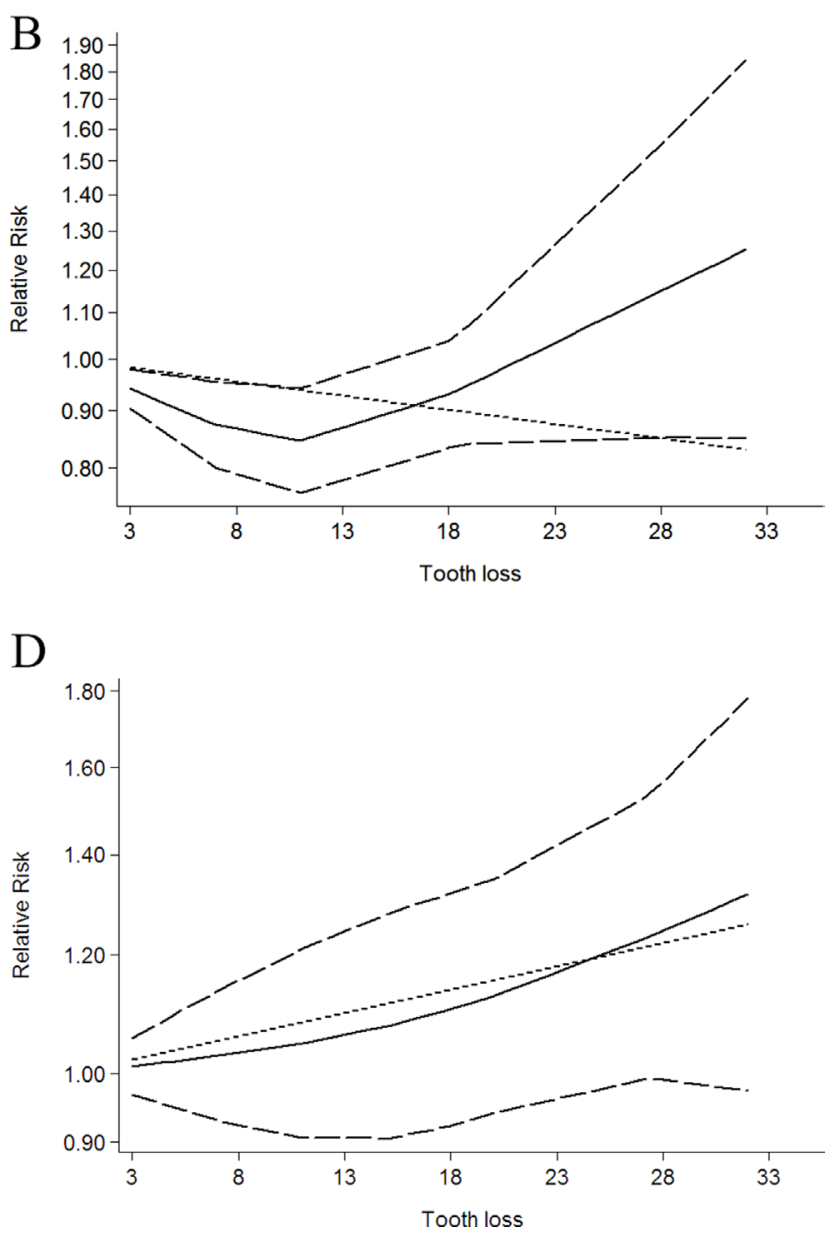

Figure 4: Dose-response relationship between tooth loss in relation to risk of cancer. (A) Bladder cancer. (B) Hematopoietic cancer. (C) Lung cancer. (D) Pancreas cancer. 
lung cancer risk (RR:1.19; 95\% CI, 1.04-1.35; $P<0.001$ ) (Figure 4). A cubic spline model revealed an positive nonlinear correlation between tooth loss and lung cancer $(P<$ 0.001 for non-linearity; Figure 4).

\section{Tooth loss and bladder cancer}

Two independent reports from two studies investigated the association between tooth loss and bladder cancer $[12,13]$. Compared with lowest tooth loss, tooth loss is significantly associated with a higher risk of bladder cancer (RR: 1.23 ; 95\% CI, $1.12-1.35$; $P$ $<0.001$ ) (Table 2). Additionally, a dose-response analysis revealed that each 10 tooth loss was associated with a $2 \%$ incremental in bladder cancer risk (RR: $1.02 ; 95 \% \mathrm{CI}$, 1.01-1.03; $P<0.001$ ) (Figure 4). A cubic spline model revealed an positive non-linear correlation between tooth loss and bladder cancer $(P<0.001$ for non-linearity; Figure 4).

\section{Tooth loss and hematopoietic cancer}

Two independent reports from two studies investigated the association between tooth loss and hematopoietic cancer $[12,13]$. Compared with the lowest tooth loss, tooth loss is significantly associated with a higher risk of hematopoietic cancer (RR: $1.07 ; 95 \% \mathrm{CI}$, $1.02-1.13 ; P<0.001$ ) (Table 2). Additionally, a doseresponse analysis revealed that each 10 tooth loss was associated with a $3 \%$ incremental in hematopoietic cancer risk (RR: 1.03; 95\% CI, 1.01-1.07; $P<0.001$ ) (Figure 4). A cubic spline model revealed an positive non-linear correlation between tooth loss and hematopoietic cancer $(P<0.001$ for non-linearity; Figure 4$)$.

\section{Subgroup analyses}

Subgroup analysis was performed to check the stability of the primary outcome. Subgroup meta-analyses in study design and study quality showed consistent findings (Table 2).

\section{Sensitivity analysis}

Sensitivity analysis was conducted to assess the stability of the results. The results show the results were stable in Supplementary Figure 1.

\section{Publication bias}

Each studies in this meta-analysis were performed to evaluate the publication bias by both Begg's funnel plot and Egger's test. $P>0.05$ was considered no publication bias. The results show no obvious evidence of publication bias was found in the associations between tooth loss and cancer risk (Supplementary Table 2).

\section{DISCUSSION}

Cancer affects millions of people in developed and developing countries that is now a public health crisis. Despite the decline in the mortality rate of developed countries, cancer is still the main cause of death and has caused serious social and economic distress on a global scale over the past few decades. In low and middle-income countries, the incidence of cancer has risen sharply [2]. To date, there are a few identified risk factors for acute pancreatitis, including smoking, infection, occupational exposure, environmental pollution, unreasonable diet and genetic factors. Previous studies indicated that tooth loss may be a risk factors in cancer, but presented controversial results.

In the current meta-analysis was based on 25 case-control or cohort study, with more than 1.3 million participants and 32925 cases from eleven countries. Thus, this meta analysis provides the most up-to-date epidemiological evidence supporting tooth loss is harmful for cancer. A dose-response analysis revealed that a per 10 of tooth loss increase was associated with a $9 \%$ increment of cancer risk, $14 \%$ increment of esophageal cancer risk, $9 \%$ increment of gastric cancer risk, $31 \%$ increment of head and neck cancer risk, $4 \%$ increment of colorectal cancer risk, 7\% increment of pancreas cancer risk, 19\% increment of lung cancer risk, $3 \%$ increment of prostate cancer risk, $2 \%$ increment of bladder cancer risk and $3 \%$ increment of hematopoietic cancer risk. Subgroup meta-analyses by various factors also showed consistent findings.

Several plausible pathways may reasonable for the relationship between tooth loss and cancer. The influence of chronic inflammation on cancer development is one possible pathway. Chronic systemic inflammation linked to periodontal disease $[36,37]$, which is a major cause of tooth loss in adults that can increase the risk of cancer by inhibiting apoptosis and stimulating tumor cell proliferation [38]. Secondly, the main cause of teeth loss is dental caries [39, 40], and carbohydrate intake is the dental caries cause. Carbohydrate intake was associated with increased risk cancer [41, 42]. Third, the progress of tooth damage destroys normal periodontal tissue, allowing oral microbial accumulation deep into oral tissue, thereby promoting its growth [43]. Thus, tooth loss and cancer seems to be closely related.

To our knowledge, this is the first study to identify and quantify the potential dose-response association between tooth loss and cancer risk in a large cohort of both men and women. Although, we performed this meta-analysis very carefully, however, some limitations must be considered in the current meta-analysis. First, different sex of population should be included in this meta-analysis to explore the impact of different sex of population on tooth loss and cancer risk. Second, we only select literature that written by English, which may have resulted in a language or cultural 
bias, other language should be chosen in the further. Third, in the subgroup analysis in cancer type, there might be insufficient statistical power to check an association. Fourth, Though some data were obtained from retrospective studies, most of retrospective studies only to identify the relationship between tooth loss and cancer risk, and we also add more study to identify and quantify the potential dose-response association between tooth loss and cancer risk.

In conclusion, our findings underscore the notion that tooth loss was associated with cancer risk increment. In the future, large-scale and population based association studies must be performed in the future to validate the risk identified in the current meta-analysis.

\section{CONFLICTS OF INTEREST}

Authors have disclosed no conflicts of interest.

\section{FINANCIAL SUPPORT}

This work was partially supported by the Initial Project for Post-Graduates of HuBei University of Medicine (K1228901).

\section{REFERENCES}

1. GBD 2015 Mortality and Causes of Death Collaborators. Global, regional, and national life expectancy, all-cause mortality, and cause-specific mortality for 249 causes of death, 1980-2015: a systematic analysis for the Global Burden of Disease Study 2015. Lancet. 2016; 388:1459-544.

2. Fitzmaurice C, Allen C, Barber RM, Barregard L, Bhutta ZA, Brenner H, Dicker DJ, Chimed-Orchir O, Dandona R, Dandona L, Fleming T, Forouzanfar MH, Hancock J, et al. Global, Regional, and National Cancer Incidence, Mortality, Years of Life Lost, Years Lived With Disability, and Disability-Adjusted Life-years for 32 Cancer Groups, 1990 to 2015: A Systematic Analysis for the Global Burden of Disease Study. JAMA Oncol. 2016; 3:524-548.

3. Pihlstrom BL, Michalowicz BS, Johnson NW. Periodontal diseases. Lancet. 2005; 366:1809-20. https://doi.org/10.1016/ s0140-6736(05)67728-8.

4. Gerritsen AE, Allen PF, Witter DJ, Bronkhorst EM, Creugers NH. Tooth loss and oral health-related quality of life: a systematic review and meta-analysis. Health Qual Life Outcomes. 2010; 8:126.

5. Adegboye AR, Twetman S, Christensen LB, Heitmann BL. Intake of dairy calcium and tooth loss among adult Danish men and women. Nutrition. 2012; 28:779-84.

6. Abnet CC, Qiao YL, Mark SD, Dong ZW, Taylor PR, Dawsey SM. Prospective study of tooth loss and incident esophageal and gastric cancers in China. Cancer Causes Control. 2001; 12:847-54.

7. Abnet CC, Kamangar F, Dawsey SM, Stolzenberg-Solomon RZ, Albanes D, Pietinen P, Virtamo J, Taylor PR. Tooth loss is associated with increased risk of gastric non-cardia adenocarcinoma in a cohort of Finnish smokers. Scand J Gastroenterol. 2005; 40:681-7.

8. Abnet CC, Kamangar F, Islami F, Nasrollahzadeh D, Brennan P, Aghcheli K, Merat S, Pourshams A, Marjani HA, Ebadati A, Sotoudeh M, Boffetta P, Malekzadeh R, et al. Tooth loss and lack of regular oral hygiene are associated with higher risk of esophageal squamous cell carcinoma. Cancer Epidemiol Biomarkers Prev. 2008; 17:3062-8.

9. Dar NA, Islami F, Bhat GA, Shah IA, Makhdoomi MA, Iqbal B, Rafiq R, Lone MM, Abnet CC, Boffetta P. Poor oral hygiene and risk of esophageal squamous cell carcinoma in Kashmir. Br J Cancer. 2013; 109:1367-72.

10. Dye BA, Wang R, Lashley R, Wei W, Abnet CC, Wang G, Dawsey SM, Cong W, Roth MJ, Li X, Qiao Y. Using NHANES oral health examination protocols as part of an esophageal cancer screening study conducted in a high-risk region of China. BMC Oral Health. 2007; 7:10.

11. Guha N, Boffetta P, Wunsch Filho V, Eluf Neto J, Shangina O, Zaridze D, Curado MP, Koifman S, Matos E, Menezes A, Szeszenia-Dabrowska N, Fernandez L, Mates D, et al. Oral health and risk of squamous cell carcinoma of the head and neck and esophagus: results of two multicentric casecontrol studies. Am J Epidemiol. 2007; 166:1159-73.

12. Hiraki A, Matsuo K, Suzuki T, Kawase T, Tajima K. Teeth loss and risk of cancer at 14 common sites in Japanese. Cancer Epidemiol Biomarkers Prev. 2008; 17:1222-7.

13. Michaud DS, Liu Y, Meyer M, Giovannucci E, Joshipura K. Periodontal disease, tooth loss, and cancer risk in male health professionals: a prospective cohort study. Lancet Oncol. 2008; 9:550-8.

14. Michaud DS, Joshipura K, Giovannucci E, Fuchs CS. A prospective study of periodontal disease and pancreatic cancer in US male health professionals. J Natl Cancer Inst. 2007; 99:171-5.

15. Shakeri R, Malekzadeh R, Etemadi A, Nasrollahzadeh D, Abedi-Ardekani B, Khoshnia M, Islami F, Pourshams A, Pawlita M, Boffetta P, Dawsey SM, Kamangar F, Abnet CC. Association of tooth loss and oral hygiene with risk of gastric adenocarcinoma. Cancer Prev Res (Phila). 2013; 6:477-82.

16. Balaram $\mathrm{P}$, Sridhar $\mathrm{H}$, Rajkumar $\mathrm{T}$, Vaccarella $\mathrm{S}$, Herrero R, Nandakumar A, Ravichandran K, Ramdas K, Sankaranarayanan R, Gajalakshmi V, Munoz N, Franceschi S. Oral cancer in southern India: the influence of smoking, drinking, paan-chewing and oral hygiene. Int $\mathrm{J}$ Cancer. 2002; 98:440-5.

17. Bundgaard T, Wildt J, Frydenberg M, Elbrond O, Nielsen JE. Case-control study of squamous cell cancer of the oral cavity in Denmark. Cancer Causes Control. 1995; 6:57-67.

18. Divaris K, Olshan AF, Smith J, Bell ME, Weissler MC, Funkhouser WK, Bradshaw PT. Oral health and risk for head and neck squamous cell carcinoma: the Carolina Head and Neck Cancer Study. Cancer Causes Control. 2010; 21:567-75. 
19. Garrote LF, Herrero R, Reyes RM, Vaccarella S, Anta JL, Ferbeye L, Munoz N, Franceschi S. Risk factors for cancer of the oral cavity and oro-pharynx in Cuba. Br J Cancer. 2001; 85:46-54.

20. Lissowska J, Pilarska A, Pilarski P, Samolczyk-Wanyura D, Piekarczyk J, Bardin-Mikollajczak A, Zatonski W, Herrero R, Munoz N, Franceschi S. Smoking, alcohol, diet, dentition and sexual practices in the epidemiology of oral cancer in Poland. Eur J Cancer Prev. 2003; 12:25-33.

21. Talamini R, Vaccarella S, Barbone F, Tavani A, La Vecchia C, Herrero R, Munoz N, Franceschi S. Oral hygiene, dentition, sexual habits and risk of oral cancer. Br J Cancer. 2000; 83:1238-42.

22. Bertrand KA, Shingala J, Evens A, Birmann BM, Giovannucci E, Michaud DS. Periodontal disease and risk of non-Hodgkin lymphoma in the Health Professionals Follow-Up Study. Int J Cancer. 2017; 140:1020-6.

23. Chen F, He BC, Yan LJ, Qiu Y, Lin LS, Cai L. Influence of oral hygiene and its interaction with standard of education on the risk of oral cancer in women who neither smoked nor drank alcohol: a hospital-based, case-control study. $\mathrm{Br}$ J Oral Maxillofac Surg. 2017; 55:260-5.

24. Chen X, Yuan Z, Lu M, Zhang Y, Jin L, Ye W. Poor oral health is associated with an increased risk of esophageal squamous cell carcinoma - a population-based case-control study in China. Int J Cancer. 2017; 140:626-35.

25. Zuo C, Zhu Y, Wang X, Zeng X, Huang C. Tooth loss and risk of oral squamous cell carcinoma in Chinese Han population. Int J Clin Exp Med. 2015; 8:21893-7.

26. Huang J, Roosaar A, Axell T, Ye W. A prospective cohort study on poor oral hygiene and pancreatic cancer risk. Int J Cancer. 2016; 138:340-7.

27. Liu Z, Chang ET, Liu Q, Cai Y, Zhang Z, Chen G, Xie SH, Cao SM, Shao JY, Jia WH, Zheng Y, Liao J, Chen Y, et al. Oral Hygiene and Risk of Nasopharyngeal Carcinoma-A Population-Based Case-Control Study in China. Cancer Epidemiol Biomarkers Prev. 2016; 25:1201-7.

28. Momen-Heravi F, Babic A, Tworoger SS, Zhang L, Wu K, Smith-Warner SA, Ogino S, Chan AT, Meyerhardt J, Giovannucci E, Fuchs C, Cho E, Michaud DS, et al. Periodontal disease, tooth loss and colorectal cancer risk: Results from the Nurses' Health Study. Int J Cancer. 2017; 140:646-52.

29. Ren HG, Luu HN, Cai H, Xiang YB, Steinwandel M, Gao YT, Hargreaves M, Zheng W, Blot WJ, Long JR, Shu XO. Oral health and risk of colorectal cancer: results from three cohort studies and a meta-analysis. Ann Oncol. 2016; 27:1329-36.
30. Stolzenberg-Solomon RZ, Dodd KW, Blaser MJ, Virtamo J, Taylor PR, Albanes D. Tooth loss, pancreatic cancer, and Helicobacter pylori. Am J Clin Nutr. 2003; 78:176-81.

31. Stroup DF, Berlin JA, Morton SC, Olkin I, Williamson GD, Rennie D, Moher D, Becker BJ, Sipe TA, Thacker SB. Meta-analysis of observational studies in epidemiology: a proposal for reporting. Meta-analysis Of Observational Studies in Epidemiology (MOOSE) group. JAMA. 2000; 283:2008-12.

32. Durrleman S, Simon R. Flexible regression models with cubic splines. Stat Med. 1989; 8:551-61.

33. Stang A. Critical evaluation of the Newcastle-Ottawa scale for the assessment of the quality of nonrandomized studies in meta-analyses. Eur J Epidemiol. 2010; 25:603-5.

34. Xu C, Zeng XT, Liu TZ, Zhang C, Yang ZH, Li S, Chen $\mathrm{XY}$. Fruits and vegetables intake and risk of bladder cancer: a PRISMA-compliant systematic review and dose-response meta-analysis of prospective cohort studies. Medicine (Baltimore). 2015; 94:e759.

35. Orsini N, Li R, Wolk A, Khudyakov P, Spiegelman D. Metaanalysis for linear and nonlinear dose-response relations: examples, an evaluation of approximations, and software. Am J Epidemiol. 2012; 175:66-73.

36. Moutsopoulos NM, Madianos PN. Low-grade inflammation in chronic infectious diseases: paradigm of periodontal infections. Ann N Y Acad Sci. 2006; 1088:251-64.

37. Loos BG. Systemic markers of inflammation in periodontitis. J Periodontol. 2005; 76:2106-15.

38. Kaaks R, Lukanova A. Energy balance and cancer: the role of insulin and insulin-like growth factor-I. Proc Nutr Soc. 2001; 60:91-106.

39. Chauncey HH, Glass RL, Alman JE. Dental caries. Principal cause of tooth extraction in a sample of US male adults. Caries Res. 1989; 23:200-5.

40. Saunders RH Jr, Meyerowitz C. Dental caries in older adults. Dent Clin North Am. 2005; 49:293-308.

41. Sanders TA. How important is the relative balance of fat and carbohydrate as sources of energy in relation to health? Proc Nutr Soc. 2016; 75:147-53.

42. Brand-Miller JC. Postprandial glycemia, glycemic index, and the prevention of type 2 diabetes. Am J Clin Nutr. 2004; 80:243-4.

43. Abnet CC, Qiao YL, Dawsey SM, Dong ZW, Taylor PR, Mark SD. Tooth loss is associated with increased risk of total death and death from upper gastrointestinal cancer, heart disease, and stroke in a Chinese population-based cohort. Int J Epidemiol. 2005; 34:467-74. 